\title{
Deletion of the Chd6 exon 12 affects motor coordination
}

\author{
Melissa J. Lathrop - Lisa Chakrabarti · Jeremiah Eng • C. Harker Rhodes • \\ Thomas Lutz • Amelia Nieto $\cdot$ H. Denny Liggitt $\cdot$ Sandra Warner • \\ Jennifer Fields $\cdot$ Reinhard Stöger $\cdot$ Steven Fiering
}

Received: 14 October 2009/ Accepted: 8 December 2009/Published online: 29 January 2010

(c) The Author(s) 2010. This article is published with open access at Springerlink.com

\begin{abstract}
Members of the CHD protein family play key roles in gene regulation through ATP-dependent chromatin remodeling. This is facilitated by chromodomains that bind histone tails, and by the SWI2/SNF2-like ATPase/helicase domain that remodels chromatin by moving histones. Chd6 is ubiquitously expressed in both mouse and human, with the highest levels of expression in the brain. The Chd6 gene contains 37 exons, of which exons 12-19 encode the highly conserved ATPase domain. To determine the biological role of $C h d 6$, we generated mouse lines with a deletion of exon 12. Chd6 without exon 12 is expressed at normal levels in mice, and Chd6 Exon $12-/-$ mice are viable, fertile, and exhibit no obvious morphological or pathological phenotype. Chd6 Exon $12-/-$ mice lack coordination as revealed
\end{abstract}

Electronic supplementary material The online version of this article (doi:10.1007/s00335-010-9248-8) contains supplementary material, which is available to authorized users.

M. J. Lathrop · S. Warner · J. Fields

Department of Microbiology/Immunology,

and Norris Cotton Cancer Center, Dartmouth Medical School,

Hanover, NH 03755, USA

\section{Chakrabarti}

School of Biosciences, University of Nottingham Medical

School, Queen's Medical Centre, Nottingham NG7 2UH, UK

L. Chakrabarti $\cdot$ J. Eng

Department of Laboratory Medicine, University of Washington

Medical Center, Seattle, WA 98195, USA

\section{Harker Rhodes}

Department of Pathology, and Norris Cotton Cancer Center,

Dartmouth Medical School, Hanover, NH 03755, USA

T. Lutz $\cdot$ A. Nieto

Centro Nacional de Biotecnología (CNB), Cantoblanco,

28049 Madrid, Spain by sensorimotor analysis. Further behavioral testing revealed that the coordination impairment was not due to muscle weakness or bradykinesia. Histological analysis of brain morphology revealed no differences between Chd6 Exon $12-/-$ mice and wild-type (WT) controls. The location of CHD6 on human chromosome 20q12 is overlapped by the linkage map regions of several human ataxias, including autosomal recessive infantile cerebellar ataxia (SCAR6), a nonprogressive cerebrospinal ataxia. The genomic location, expression pattern, and ataxic phenotype of Chd6 Exon $12-/-$ mice indicate that mutations within CHD6 may be responsible for one of these ataxias.

\section{Introduction}

Dynamic remodeling of the chromatin structure during DNA replication, repair, recombination, and transcription

H. Denny Liggitt

Department of Comparative Medicine, University of

Washington, Health Sciences Center, Seattle, WA 98195, USA

R. Stöger ( $\square)$

School of Biosciences, University of Nottingham, Sutton

Bonington Campus, Leicestershire LE12 5RD, UK

e-mail: Reinhard.Stoger@nottingham.ac.uk

\section{S. Fiering}

Departments of Microbiology/Immunology and Genetics, and Norris Cotton Cancer Center, Dartmouth Medical School, Hanover, NH 03755, USA

S. Fiering ( $\square)$

One Medical Center Drive, Rubin Building Room 623,

Lebanon, NH 03756, USA

e-mail: Fiering@dartmouth.edu 
is a vital facet of eukaryotic DNA metabolism and involves changes and modifications of DNA-protein interactions. The position of a nucleosome relative to a given DNA sequence directly influences the plasticity of chromatin and transcription of nearby genes (de la Serna et al. 2006). The processes of nucleosome sliding and nucleosome displacement are energy dependent and carried out by members of the sucrose nonfermenting 2 (SNF2) superfamily of DNA-dependent ATPase proteins (reviewed in Brown et al. 2007), which function in large multiprotein chromatin-remodeling complexes.

Chromodomain-Helicase-DNA-binding (CHD) proteins make up one family of SNF2-like chromatin-remodeling enzymes. The family name is based upon the distinct combination of structural domains common to all CHD enzymes; tandem N-terminal Chromodomains, followed by a SWI2/SNF2-like Helicase/ATPase domain, and a C-terminal portion with less well characterized DNA-binding capability (Delmas et al. 1993; reviewed in Hall and Georgel 2007; Marfella and Imbalzano 2007). The catalytic SWI2/SNF2-like helicase/ATPase chromatin-remodeling domain shares sequence similarities with bacterial RecAlike helicase domains.

The SWI2/SNF2-like ATPase domain contains seven motifs that are conserved throughout evolution (Eisen et al. 1995; Singleton and Wigley 2002; Thoma et al. 2005). Motif I was first characterized by Walker et al. (1982) and plays a critical role in the catalytic function of the ATP binding pocket. Within motif I there are 15 amino acids that are very highly conserved, 9 of which are $100 \%$ conserved among the 16 SNF2 family members compared here (Supplementary Fig. 1). Point mutation of key conserved residues in any of the seven motifs has been shown to remove function of the domain (Richmond and Peterson 1996). Mutation of the lysine within the $100 \%$ conserved GLGKT sequence of motif I has repeatedly been shown to result in complete loss of ATPase function of SNF2 family members (Citterio et al. 1998, 2000; Khavari et al. 1993; Laurent et al. 1993), including the recent characterization of Chd8 (Thompson et al. 2008). Several human diseases are associated with mutations within the SWI2/SNF2-like ATPase domain, indicating the importance of the ATPase domain in protein function. Mutations within the ATPase domain of Cockayne syndrome B protein result in ultraviolet sensitivity and neurodevelopmental abnormalities (Citterio et al. 2000), while mutations in the ATRX ATPase domain cause $\alpha$-thalassemia/mental retardation syndrome, X-linked (ATR-X syndrome) (Wada et al. 2000).

There are nine CHD proteins in both human and mouse genomes [NCBI UaWE, Consensus CDS (CCDS) project in build for 36.3/37.1, 2008] and they are divided into three subfamilies based on the presence of other protein domains (Schuster and Stöger 2002). Mutations in subfamilies I and
II are associated with developmental defects (Kulkarni et al. 2008; Williams et al. 2004; Yoshida et al. 2008) and perinatal lethality in mice (Marfella et al. 2006). Genes CHD5-CHD9 encode the proteins that make up CHD subfamily III. Currently, mutations within two CHD genes from subfamily III are associated with pathology. CHD5 is a tumor suppressor gene, mutations of which contribute to neuroblastoma (Bagchi et al. 2007; Fujita et al. 2008; Thompson et al. 2003; White et al. 2005), while mutations of $C H D 7$ account for over $60 \%$ of individuals affected by CHARGE syndrome, a complex congenital disorder characterized by developmental malformations of the eye, ear, heart, and genitals as well as cognitive impairment (Aramaki et al. 2006; Pagon et al. 1981; Vissers et al. 2004). These and related findings highlight the essential role of CHD family members in normal neural development and brain function (Bultman et al. 2000; Picketts et al. 1996; reviewed in Brown et al. 2007; Hsieh and Gage 2005).

CHD6 (formerly called CHD5) is the founding member of CHD subfamily III (Schuster and Stöger 2002). First identified based on the highly conserved ATPase domain, the additional presence of ill-defined domains that make up the DNA-binding domain distinguished CHD6 from subfamilies I and II (Fig. 1a). CHD6 is a ubiquitously expressed gene (Lutz et al. 2006; Schuster and Stöger 2002) and is particularly abundant in regions of the adult mouse brain, such as the cerebellum, medulla, globus pallidus, and the retrohippocampal area (Lein et al. 2007; Su et al. 2004). CHD6 is a large (2711 amino acids) nuclear protein that colocalizes with RNA polymerase II during preinitiation and elongation stages of RNA synthesis, suggesting that this chromatin-remodeling enzyme plays a role in modulating and facilitating the transcription of target genes, which have yet to be identified (Lutz et al. 2006). CHD6 precipitates as part of a large complex of proteins and has been shown to function in the phase-two stress response pathway by interaction with the NFE2 related factor 2 (NRF2) transcription factor to regulate expression of $N Q O 1$ (Nioi et al. 2005). We previously demonstrated that $C H D 6$ is a DNAdependent ATPase with a functional SNF2/SWI2-like helicase/ATPase domain (Lutz et al. 2006).

The biological and physiological importance of CHD6 is not known. A recent case study of a chromosomal translocation between CHD6 and the basic helix-loop-helix transcription factor 4 (TCF4) gene identified a phenotype of mental retardation without Pitt-Hopkins syndrome characteristics that was attributed to the truncation of TCF4, but the resulting effect on CHD6 expression and function was not determined (Kalscheuer et al. 2008). Several human ataxias have linkage map regions that encompass the position of CHD6 on chromosome 20q12 (Bennetts et al. 2007; Hertz et al. 2004; Tranebjaerg et al. 2003). 

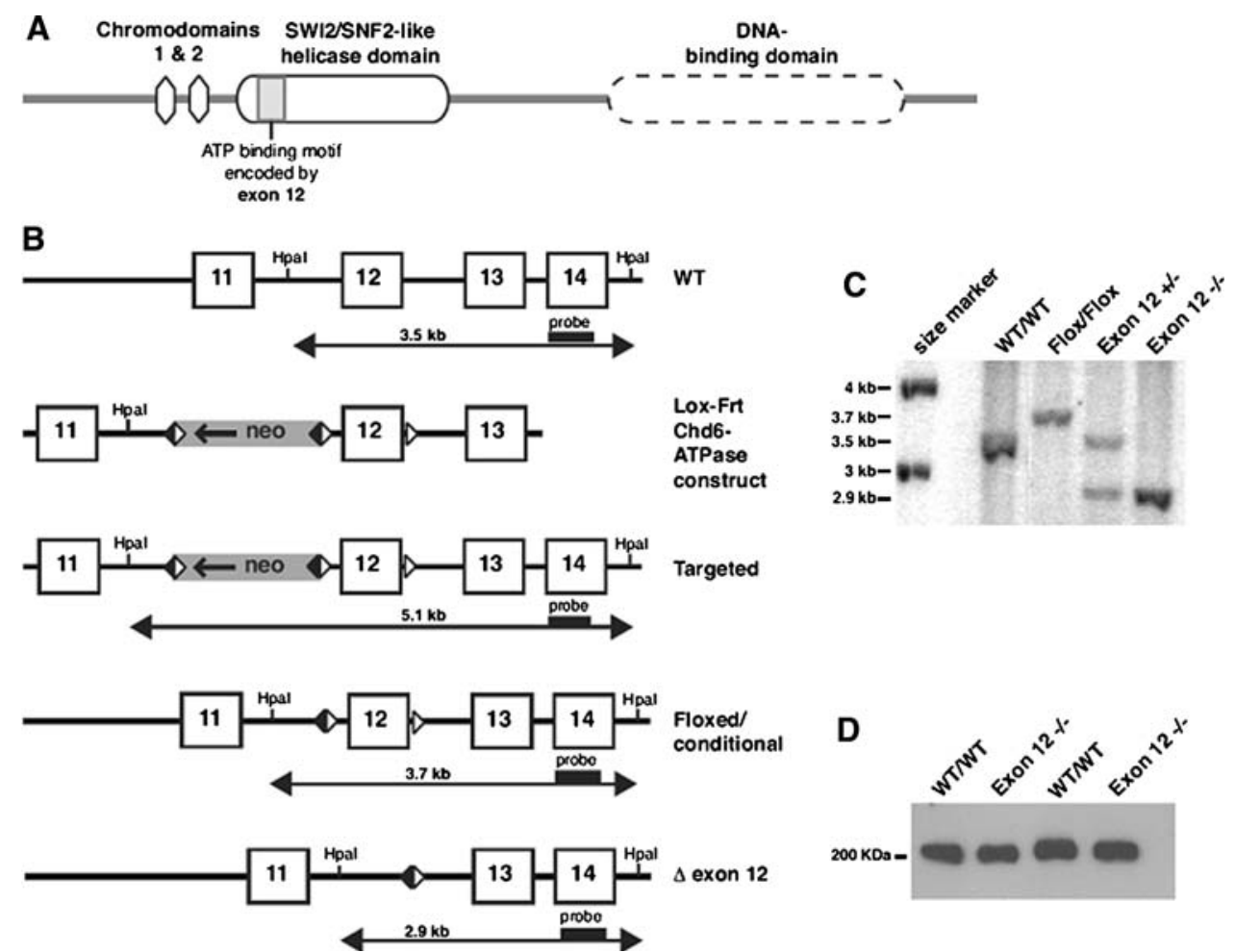

Fig. 1 Generation of a Chd6 Exon 12 -/- mouse line. a Domain architecture of the Chd6 protein. The SWI2/SNF2 helicase domain contains seven conserved motifs, including motif I (ATP-binding region) and Ia (DNA binding), which are encoded by exon 12 of $m C h d 6$. b Gene targeting strategy: A portion of the $m C h d 6$ gene structure is shown, including exons 11-14 (boxes), and the HpaI restriction enzyme sites used for Southern blot analysis. The targeting vector "lox-frt-Chd6-ATPase" was designed to enable the deletion of $m C h d 6$ exon 12 by loxP site-specific recombination. The loxP sites (white triangles) and direction of transcription of the Neomycinresistance gene (Neo) are indicated (arrow). The Frt-flanked Neocassette was removed by flp-mediated, site-specific recombination

To assess the functional role of Chd6 we generated a Chd6 Exon $12-/-$ mouse. Because exon 12 encodes a highly conserved portion of the ATPase domain, it is expected that this deletion inactivates the ATPase domain, but this expectation has not been experimentally addressed. A splice from exon 11-13 is in-frame and the mutant protein is expressed at normal levels. The homozygous mutant mice are viable and fertile and have no obvious phenotype. Behavioral testing revealed that homozygous Chd6 Exon 12 -/- animals exhibit coordination defects most consistent with a cerebellar neuron disorder.

\section{Materials and methods}

Generation of the mutant ES cells and mice

The conditional deletion of exon 12 of the mouse Chd6 gene utilized a targeting construct that contains an Frt/loxP
(Frt recombination elements are black triangles). The structure of the desired allele ( $\Delta$-exon 12$)$ was obtained after Cre-mediated excision of the floxed exon 12. The Southern probe and the sizes of HpaI restriction fragments detected by this probe in wild-type (WT) and targeted DNA are shown. c Southern analysis of tail clip genomic DNA: The WT Chd6 allele ( $3.5 \mathrm{~kb}$ band) is distinguishable from the floxed conditional Chd6 allele $(3.7 \mathrm{~kb})$ and the Chd6 Exon $12-/-$ allele $(2.9 \mathrm{~kb})$. d Western analysis: Detection of WT Chd6 (305 kDa) and mutant $\Delta 479-558 C h d 6(296 \mathrm{kDa})$ in lung extracts from WT and Chd6 Exon 12 -/- animals, respectively. The small difference in molecular weights between WT and mutant Chd6 could not be detected by this assay

flanked neomycin cassette positioned $5^{\prime}$ of exon 12 , with a third loxP site inserted $3^{\prime}$ to the exon (Fig. 1b). The integrity of the lox-frt-Chd6-ATPase construct was confirmed by restriction digestion and sequencing of Chd6 exons 11,12 , and 13 , including the intron-exon boundaries.

Using standard techniques (Nagy 2003), targeted 129 SvIMJ embryonic stem (ES) cells were generated and C57BL/6/129 SvIMJ mouse lines were developed from one correctly targeted ES cell clone. The presence of the targeted allele was identified by PCR and Southern blot. Mixed WT mice were derived from homozygous wild-type littermates of mutant mice and were maintained with breeding strategies identical to those for the mutant mice by the intercross of multiple-mating pairs with the appropriate genotype. For genotyping of animals, genomic DNA was isolated from mouse tails using the Gentra Puregene kit (Qiagen, Valencia, CA, USA) followed by phenol-chloroform extraction. The derived animals were mated to mice that express either Cre in the germline $\left(\mathrm{Jax}^{\circledR}\right.$ Mice, stock 
number 003465) to generate Exon 12 -/- alleles (Chd6 Exon $12-/-$ mice), or flp in the germline $\left(\mathrm{Jax}{ }^{\circledR}\right.$ Mice, stock number 003800) to delete the selectable marker but leave the ATPase domain intact (mixed WT). Deletion of exon 12 was confirmed in genomic DNA by PCR and in the expressed mRNA by RT-PCR and sequencing of the exon 11-13 junction (data not shown) (see Table 1 for primer sequences). Mice were either maintained in a mixed genetic background or backcrossed into the $129 \mathrm{SvImJ}$ parental strain $\left(\mathrm{Jax}^{\circledR}\right.$ Mice, stock number 002448) until they were 97\% 129 genetically (N5), at which point heterozygotes were crossed to produce the homozygous 129 Exon 12 -/line. All mouse work was performed under protocols approved by the Dartmouth IACUC.

Physiological analysis of mutant mice

Physiological analysis of the mice included observations of appearance and behavior in the home cage, weight from 3 to 28 weeks of age, the effect of consuming high- and lowfat diets, and histological analysis of every major tissue and organ. Samples of each tissue were embedded in paraffin for sectioning and histological analysis of morphology and cellular structure (see Supplementary Methods for detailed descriptions). Mice were sacrificed by avertin overdose and whole blood was obtained by cardiac puncture. Blood was collected either without anticoagulant or into $\mathrm{K}_{2}$ EDTA for analysis of serum chemistry or complete blood count, respectively; analysis was performed by Charles River Laboratories (Wilmington, MA, USA). Protein was isolated from individual tissues and Chd6 Western analysis was performed as previously described in Lutz et al. (2006).

\section{Behavioral analysis}

For the ledge test, mice were placed on the $0.75 \mathrm{~cm}$ edge of a cage and allowed to either progress along the ledge, climb down head first in a controlled manner, fall off hind feet first in an uncontrolled manner, or sit stationary for up to $3 \mathrm{~min}$. Collected data were distance traveled if they moved, or if they did not, the type of descent or whether they were stationary for the $3 \mathrm{~min}$ trial.

Behavioral analysis of age/gender-matched mice began at 8 weeks of age using mice with known genotypes. Male and female animals performed equally in all tests so we interpreted the results based solely on genotype. The data are represented as the average for all mice of each genotype used (Crawley 2007). The mice were put through a battery of tests in the following order: open field maze, Barnes maze, pole test, and rotorod. Later tests were added, including wire-hang, beam-walking, and olfactory tests, which were performed at age 18 weeks or at age 10 weeks. Age-specific differences were not observed in the wirehang or beam-walking tests between the early and later test groups so the data were pooled for genotype analysis.

Mice were trained on the accelerating rotorod (model 775, IITC, Woodale, CA, USA) for 2 days and tested for 3 days. The mouse is placed on the rod as it slowly accelerates and the rotational speed at which the mouse falls off is recorded. Each trial consisted of the rotorod accelerating from 1 to $40 \mathrm{rpm}$ over $120 \mathrm{~s}$, with up to $10 \mathrm{~s}$ at $40 \mathrm{rpm}$. Three trials were performed each day for three consecutive days with a $6 \mathrm{~min}$ rest between trials. Mice that accomplish motor learning will improve in performance (higher rpm before falling off) with each trial. Mice will often regress partially for the first trial of the following day, resulting in a stepped pattern. Trials in which mice fell off the rod when rotating slower than $2 \mathrm{rpm}$ were not included in the data and the trial was repeated. Detailed methods for behavioral analysis are provided as supplementary methods; a detailed chart of the behavioral analysis data is included as Supplementary Table 1. Statistical analysis was performed with $\mathrm{R}$ software (version 2.5.0; http://www.r-project.org). Data were analyzed by Welch's $t$ test and significance was determined as $P<0.05$.
Table 1 Primers used in the phenotype assessment of Chd6 Exon $12-/-$ mice

\begin{tabular}{|c|c|c|}
\hline Name & Primer sequence $5^{\prime}-3^{\prime}$ & Annealing Tm/product size \\
\hline Exon $12-/-$ foward & GACATACACAATGGCATGTATGCT & $60^{\circ} \mathrm{C}$ \\
\hline Exon $12-/-$ reverse & GTGTACCATCATGCCTGACTCAC & 345 bp (-/-), 900 bp (WT) \\
\hline WT forward & АCССАТАСТТСТТАСССТСТGCAG & $60^{\circ} \mathrm{C}$ \\
\hline WT reverse & GTGTACCATCATGCCTGACTCAC & 605 bp (WT) \\
\hline Exon 11 forward & GAAACTGGAGACATCCCGTG & $61{ }^{\circ} \mathrm{C}$ \\
\hline Exon 13 reverse & GCAGTTCCTATTCTTCAGTCT & 238 bp (-/-), 483 bp (WT) \\
\hline Nqo1 forward & ACAGGTGAGCTGAAGGACTC & $57^{\circ} \mathrm{C}$ \\
\hline Nqo1 reverse & CTGCTACGAGCACTCTCTCA & $202 \mathrm{bp}$ \\
\hline$\beta$-actin forward & GTGGGCCGCTCTAGGCACCA & $57^{\circ} \mathrm{C}$ \\
\hline$\beta$-actin reverse & CGGTTGGCCTTAGGGTTCAGG & $245 \mathrm{bp}$ \\
\hline
\end{tabular}


Immunohistochemistry

Brains from Chd6 Exon 12 -/- mice and WT controls were prepared at approximately 17 weeks of age by perfusion with $4 \%$ paraformaldehyde. Immunohistochemistry was carried out as previously described using standard procedures and with antibody dilutions recommended by the manufacturers (Chakrabarti et al. 2006). Counterstain of nuclei was achieved using a DAPI type reagent (Hoechst-H stain). Histology with Cresyl violet was performed on dewaxed sections.

\section{Oxidative stress response analysis}

Induction of the stress response pathway followed by reactive oxygen species challenge was measured by flow cytometry. Mouse embryonic fibroblast (MEF) cells from mixed WT and mixed Exon $12-/-$ embryos were cultured and then treated with vehicle control or 1-[2-cyano-3,12dioxooleana-1,9(11)-dien-28-oyl]imidazole (CDDO) for $18 \mathrm{~h}$. Cells were harvested and treated with $2^{\prime}, 7^{\prime}$-dichlorodihydrofluorescein diacetate (DCFDA) or vehicle for 15 min before addition of tert-butyl hydroperoxide (tBHP) or vehicle. FACScan (Becton-Dickinson, San Jose, CA) analysis measured the change in fluorescence intensity. Stress response stimulation of the $N r f 2$ pathway was determined by qPCR analysis of $\mathrm{Nqol}$ gene expression. Mixed WT and mixed Exon 12 -/- MEFs cells were treated with DMSO vehicle control, $5 \mu \mathrm{M}$ sulforaphane, or $100 \mathrm{nM}$ CDDO for $20 \mathrm{~h}$. RNA was isolated using the RNeasy kit (Qiagen, Valencia, CA, USA) and reverse transcribed. Nqol and $\beta$-actin expression levels were assayed by iQ SYBER Green PCR (Bio-Rad, Hercules, CA, USA), with Nqol normalized to $\beta$-actin expression (see Table 1 for primer sequences).

\section{Results}

Exon $12-/-$ mice do not show obvious anatomic or pathologic phenotype

To test the biological importance of Chd6 we generated a conditional knockout mouse line that enables the deletion of Chd6 exon 12 (Fig. 1). To avoid interference of the selection marker with expression of Chd6, the Neomycin resistance gene was removed by $f p$-mediated, site-specific recombination. Mice with a correctly targeted allele (Targeted) were crossed with C57BL/6 mice expressing flp in the germline to generate the conditional (floxed) allele mice (mixed WT), or with Cre-expressing BALB/c mice to generate the Exon 12 $-/-$ mice (mixed Exon $12-/-$ ) (Fig. 1b). Heterozygous and homozygous targeted mice were identified through
Southern blotting (Fig. 1c). Deletion of exon 12 removes 81 amino acids of the SWI2/SNF2-like domain which encodes motif I, a key ATP-binding motif, and motif Ia, which has DNA-binding activity (Durr et al. 2005). Exon 11 is spliced in-frame with exon 13 and the Exon $12-/-$ protein is synthesized at WT levels (Fig. 1d).

Exon $12-/-$ mice on a mixed C57BL/6/129 Sv/BALB/ c genetic background (mixed Exon $12-/-$ ) are viable and fertile and born in normal Mendelian ratios. Mixed Exon $12-/-$ mice were compared to mixed lineage mice that had a floxed conditional exon 12 allele but did not have the deletion (mixed WT). Pathological analysis of mixed Exon 12 -/- mice included histological analysis of tissues (including lung, bone marrow, skin/fat, liver, gastrointestinal tract, spleen/lymph nodes, kidney, pancreas, brain, heart, thymus, skeletal muscle, and testis or uterus) at two developmental time points, 26 days or 90 days of age; there were no differences in any tissue (data not shown). Whole blood and serum analysis revealed no changes in complete blood counts or serum chemistry (data not shown). Analysis of mouse body weight while consuming both high-fat and low-fat diets identified no difference between mixed Exon $12-/-$ and mixed WT animals in body mass and did not indicate any metabolic deficiencies (Supplementary Fig. 2). Mouse embryonic fibroblast (MEF) cell lines of mixed Exon $12-/-$ mice and mixed WT mice were used to determine that there was no difference in the DNA repair pathways of the Chd6 Exon 12 $-/-$ mice, and analysis of splenocytes by flow cytometry (FACScan analysis) indicated that there was no difference in the cell cycle dynamics (data not shown).

To further determine potential strain-specific phenotypes, the Exon $12-/-$ line was backcrossed into the 129 SvImJ parental strain until it was $97 \%$ pure $129 \mathrm{~Sv}$ statistically (N5 generation), at which point heterozygotes were crossed to produce homozygous 129 SvImJ Chd6 Exon $12-/-$ mice (129 Exon $12-/-$ ), which were then compared to pure $129 \mathrm{SvImJ}$ strain (129 WT) from The Jackson Laboratory (Bar Harbor, ME, USA). 129 Exon 12 $-/-$ mice also exhibit no developmental problems and are born in expected Mendelian ratios.

Behavioral studies reveal Exon 12 -/- mice have impaired coordination and balance

The analysis of potential phenotypes included behavioral studies, as Chd6 is highly expressed in the brain and particularly in the cerebellum (Lein et al. 2007; Su et al. 2004). Mice from both mixed and 129 Sv genetic backgrounds displayed no difference in behavior when observed while in the home cage. However, a preliminary test of neurological function, the ledge test (Chen et al. 2005), indicated a coordination deficiency. 
The ledge test measures the behavior of a mouse placed along the $0.75 \mathrm{~cm}$-wide ledge of a mouse cage over a specified period of time. The mice were scored for movement along the ledge and if they did not progress, they were scored on whether they sat still for a full 3 min until removed, fell off the ledge, or made a controlled descent. Most mixed WT mice progressed $(n=13)$ with an average progression of $47 \mathrm{~cm}$ compared with the average distance of $3 \mathrm{~cm}$ per mouse observed in mixed Exon $12-/-$ mice $(n=10)$, most of whom did not progress (Fig. 2a). Of the mixed WT that did not progress, most climbed into the cage in a controlled manner head first, and a small percentage either did not move or fell off the ledge (Fig. 2b). 129 WT $(n=11)$ and 129 Exon $12-/-$ mice $(n=17)$ were equally unlikely to progress and there was no difference between the progression distances in the 129 strains (Fig. 2c). Most of the 129 Exon $12-/-$ fell into the cage and rarely climbed down, while 129 WT generally either climbed down or sat still and never fell (Fig. 2d). The ledge test shows that there is a clear difference in the ability of Exon $12-/-$ mice to move on the ledge or descend in a controlled manner, regardless of the genetic background. The inability to progress along the ledge or descend off the ledge in a controlled, head-first manner suggests a deficiency in motor coordination in the Exon 12 $-1-$ mice.

Several conditions may result in loss of motor coordination, including muscle weakness and ataxia (impaired coordination or balance) (Gowen and Miall 2007). Following the indication of impaired motor coordination, Exon $12-/-$ mice from both mixed lineage and $129 \mathrm{~Sv}$ backgrounds were analyzed with a battery of behavioral tests, including sensorimotor assays.

The rotorod assay measures motor coordination and, with repeated trials is able to assay motor learning (Crawley 2007). The impaired ability of the Exon 12 -/mice to run on the rotorod at greater than moderate speeds is the most obvious and highly significant phenotype of the behavioral testing $(P<0.0001)$. Mixed Exon $12-/-$ mice $(n=21)$ fell off significantly earlier than the mixed WT controls $(n=21)$ in every trial (Fig. 3a). This was true for all three trials run on a given day and for all 3 days of testing. It was common for the mixed WT mice to reach the top speed tested on the rotorod (40 rpm) and maintain that pace, while this was highly unusual for mixed Exon 12 $-/-$ mice. The 129 Exon $12-/-$ mice $(n=13)$ also fell
A

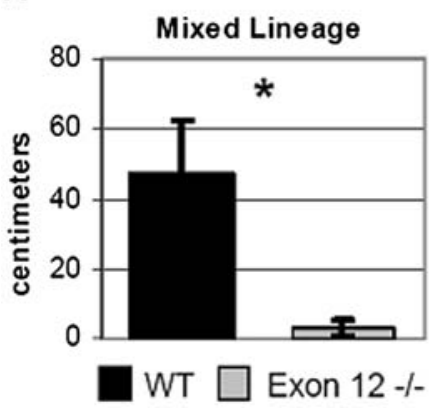

C

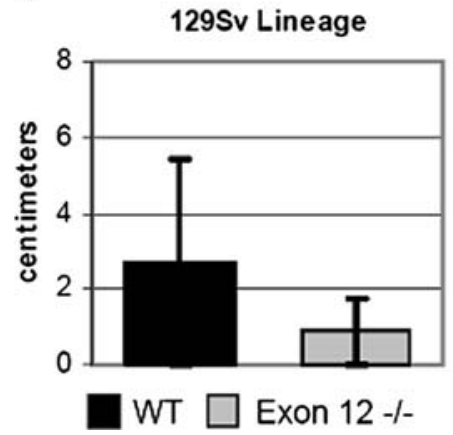

B
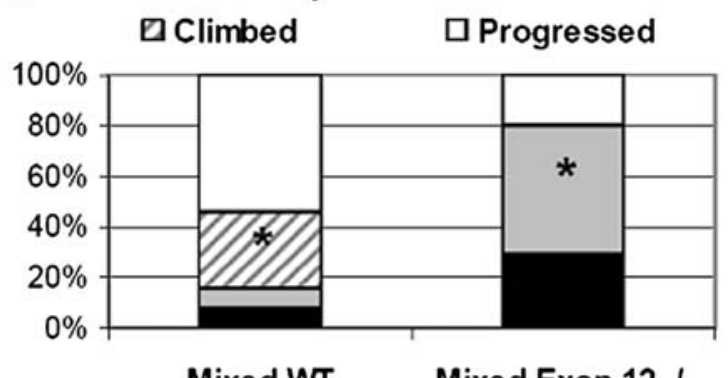

D

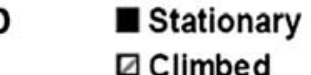
$\square$ Climbed

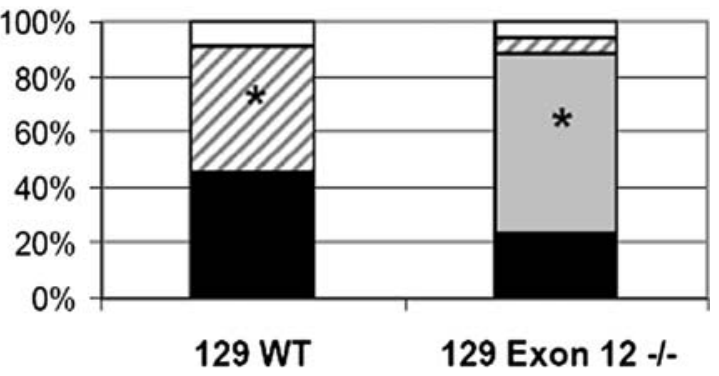

Fig. 2 Exon $12-/-$ mice are impaired in the ledge test compared to WT mice. Mice were placed on the $0.75 \mathrm{~cm}$-wide ledge of a mouse cage and observed for $3 \mathrm{~min}$. Mice were scored as having performed one of four behaviors: remaining stationary on the ledge, falling off the ledge, climbing into the cage in a controlled manner, or progressing along the ledge. a Average distance progressed by mixed lineage WT and Exon $12-/-$ mice. b Percent of mixed lineage mice to perform each behavior. c Average distance crossed by $129 \mathrm{~Sv}$ lineage Exon $12-/-$ and WT mice. d Percent of 129 Sv lineage mice to perform each behavior. Data are represented as a percentage of the total number of mice tested. Error bars are \pm SEM, significant difference is indicated by $*(P<0.05$ for the same behavior compared between WT and Exon $12-/-$ of the same lineage) 
off significantly earlier than the 129 WT mice $(n=17)$ for every trial (Fig. 3b). Interestingly, motor learning was not affected by the deletion of the Chd6 exon 12 . All groups of mice generally improve the average trial rpm over the three trials of a given day (Fig. 3a, b). This manifestation of motor learning is particularly clear for the 129 lineage. This learning is not fully retained overnight as the first trial of a new day of testing has a lower average than the last trial of the previous day, but there was some retained motor learning because often a given day's averages are higher than those of previous days. For all trials, the average maximum rpm that the mixed Exon $12-/-$ mice reached before falling was $19.4 \mathrm{rpm}( \pm 2.46 \mathrm{SEM})$. This is

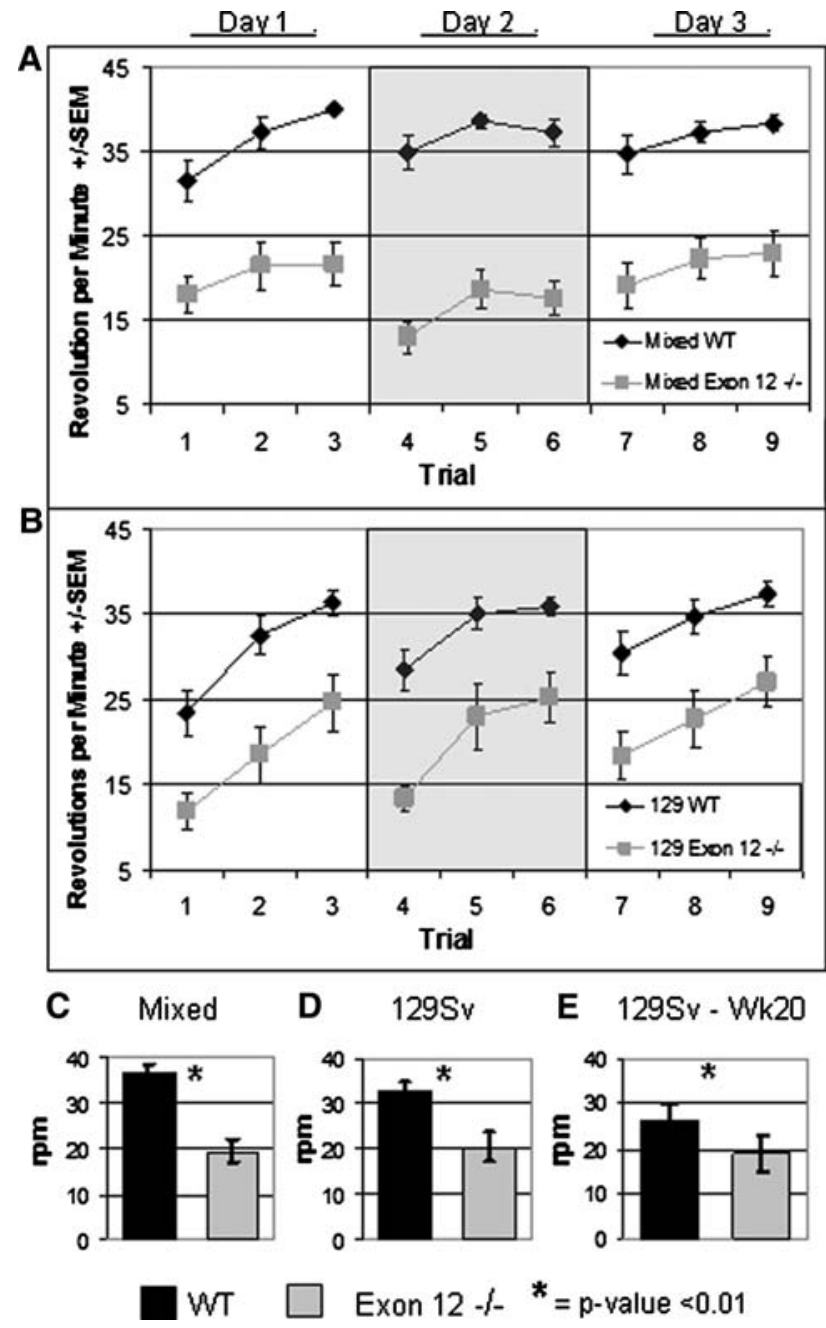

Fig. 3 Exon 12 -/- mice have impaired rotorod performance. Mice were tested for 3 days, with three trials per day for a total of nine trials. a Average rpm reached for individual trials with mixed lineage mice. b Average rpm reached for individual trials with $129 \mathrm{~Sv}$ lineage mice. For both lineages, in each trial the WT results are significantly different from the Exon $12-/-$ results $(P<0.01)$. c Average rpm for all trials with mixed lineage mice. d Average rpm for all trials with $129 \mathrm{~Sv}$ lineage mice. e Average rpm for all trials with $129 \mathrm{~Sv}$ lineage mice tested at week 20 . Error bars are \pm SEM, Significance of $P<0.01$ is indicated by $*$ significantly slower than the mixed WT mice, which averaged $36.6 \mathrm{rpm}( \pm 1.68)$ before falling (Fig. 3c). For all trials, the average maximum rpm that the 129 Exon $12-/-$ mice reached before falling was $20.51 \mathrm{rpm}( \pm 3.19)$, and the average for the $129 \mathrm{WT}$ control group was $32.6 \mathrm{rpm}$ (土2.21) (Fig. 3d).

The lack of coordination seen in both the ledge test and the rotorod and the high levels of Chd6 present in the cerebellum (Lein et al. 2007) are indicative of an ataxia phenotype caused by neural impairment. To determine whether the impaired coordination of the Exon $12-/-$ mice was due to a progressive ataxia, 129 Exon 12 -/mice and 129 WT mice that had previously run the rotorod apparatus at 10 weeks of age were tested again at 20 weeks of age. The ability of aged 129 WT mice $(n=9)$ to run on the rotorod was diminished (129 WT, $32.6 \mathrm{rpm}$; aged 129 WT, $26.2 \mathrm{rpm}$ average), and the aged 129 Exon $12-/-$ mice $(n=6)$ had a slightly reduced performance (129 Exon 12 -/-, $20.5 \mathrm{rpm}$; aged 129 Exon 12 -/-, $18.9 \mathrm{rpm})$. The difference in aged $129 \mathrm{WT}$ performance and aged 129 Exon $12-/-$ performance continued to be significant, but it did not increase appreciably (Fig. 3e), indicating that the ataxia is not strongly progressive between 10 and 20 weeks of age.

Mice may display impaired ability during the rotorod assay for several reasons such as poor coordination or balance, bradykinesis (slowed movement) (Ogawa et al. 1985), increased weight (Cook et al. 2002; McFadyen et al. 2003), or muscular deficiencies (Koch et al. 2008). Previous studies had determined no difference in the weights of the mice (Supplementary Fig. 2). To investigate the impaired movement of Chd6 Exon $12-/-$ mice, further behavioral tests were performed.

To determine whether muscle weakness was the cause of the poor rotorod performance, the wire-hang test was performed on all lineages (mixed WT, $n=18$; mixed Exon $12-/-, n=14 ; 129$ WT, $n=12$; 129 Exon $12-/-$, $n=9)$. The wire-hang test directly measures the ability of the mouse to hang from a wire grid, reflecting muscle strength (Crawley 2007). Exon 12 -/- mice in both lineages performed as well as their WT counterparts in the wire-hang test (Fig. 4a, b).

The pole test is used to identify bradykinesis and also is indicative of muscle strength (Berardelli et al. 2001; Bouet et al. 2007) and proper dopaminergic neuronal signaling (Iwamoto et al. 2003; Matsuura et al. 1997). The pole test determines whether mice placed head up on a thin upright pole can both successfully invert and travel down the pole. Mixed Exon $12-/-$ mice $(n=20)$ and 129 Exon $12-/-$ mice $(n=9)$ were able to invert (Fig. 4c, d) and descend (Fig. 4e, f) the pole in times similar to those of the mixed WT $(n=21)$ and 129 WT mice $(n=12)$. Results from the wire-hang and pole tests suggest that the difficulty in the 
rotorod test is not likely due to poor muscle development or bradykinesis.

The beam-walking test measures both coordination and balance by assessing the ability to walk across a tapecovered cylindrical beam $(1.5 \mathrm{~cm}$ wide and $61 \mathrm{~cm}$ long) and enter the home cage (Crawley 2007). The mixed Exon 12 -/- mice have impaired beam-walking ability compared with controls. Thirteen of 21 mixed WT mice walked the beam and successfully entered the home cage, while 1 of 17 mixed Exon $12-/-$ mice walked the beam and entered the home cage (Fig. 4g). Both 129 WT $(n=12)$ and 129 Exon $12-/-(n=9)$ mice performed reasonably well on the beam-walking test (Fig. 4h), though a lower percentage of 129 mice performed the task compared to mixed lineage mice.

The majority of the mixed Exon $12-/-$ mice did not fall off while attempting to cross the beam; they jumped off into the test area from the start location. This could be because they lack the coordination and balance to cross the beam or because of an impaired olfactory capacity. The mixed Exon $12-/-$ mice may have been unable to smell their home cage and thus had no desire to travel along the beam. However, an olfactory test determined that mixed Exon $12-/-$ mice are able to smell. After an $18 \mathrm{~h}$ fast the mice were given $3 \mathrm{~min}$ to find a piece of food hidden under bedding in a clean cage. Five of six mixed Exon $12-/-$ mice found the food, while only two of six of the mixed WT mice accomplished this (Fig. 4i).

The open-field test directly measures the level of anxiety in the mouse. The test measures the amount of time a mouse spends in the center of an open field compared to time spent along the wall. Higher anxiety levels are demonstrated by increased time spent near the wall. The mixed Exon $12-/-$ mice $(n=17)$ displayed slightly increased anxiety compared with mixed WT $(n=20)$, with a ratio of center to wall of $0.144( \pm 0.035)$ for the mixed Exon 12 $-/-$ and $0.342( \pm 0.057)$ for the mixed WT indicating less anxiety (Fig. 5a). The mice showed no difference in other parameters measured by this test, including distance traveled (Fig. 5b) or ambulatory time (Fig. 5c). No difference was observed between $129 \mathrm{WT}$ and 129 Exon $12-/-$ mice in the open-field test (data not shown). An increased level of anxiety is characteristic of the $129 \mathrm{SvImJ}$ mouse strain (Hagenbuch et al. 2006), and 129 WT and 129 Exon 12 $-/-$ mice exhibited similarly high levels of anxiety in this test.

To further explore the differences in anxiety levels in Exon $12-/-$ mice, the Barnes maze was used to study spatial learning ability as well as anxiety levels. The Barnes maze consists of a bright open circular platform with 40 holes along the edge, with a dark goal box beneath one hole into which the mouse can climb down and hide. Mice with higher anxiety levels will use spatial cues to
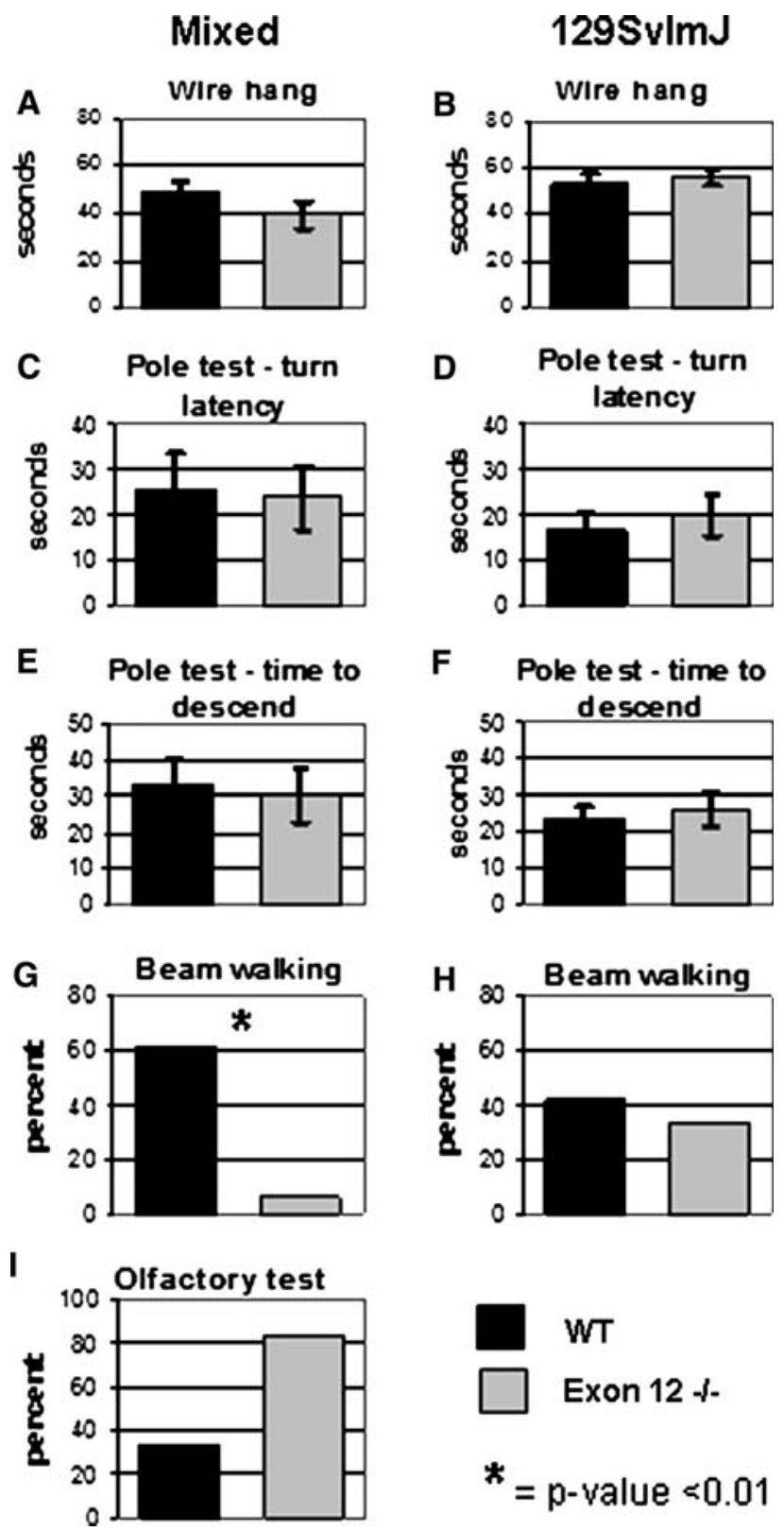

Fig. 4 Behavior analysis of Exon 12 -/- mice demonstrates further evidence that the sensorimotor defect is not due to muscle weakness or bradykinesis. The average for all trials is indicated for mixed lineage and $129 \mathrm{~Sv}$ lineage mice were tested on the wire hang (a, b), pole test (c-f), beam walking $(\mathbf{g}, \mathbf{h})$, and olfaction (i). Black bars indicate WT mice values; gray bars indicate Exon 12 -/- mice values. Error bars are \pm SEM. For beam-walking and olfaction test data, the number of mice to accomplish the task is represented as a percent of the total number tested. Significance of $P<0.01$ is indicated by $*$

learn where the goal box is located and will enter more quickly to escape the bright platform than less anxious control mice (Crawley 2008). The results of the Barnes maze studies indicated that mixed Exon $12-/-$ mice $(n=21)$ had no deficiency in spatial learning, no increase in anxiety, and there is no impairment in vision compared 
Fig. 5 Behavioral analysis of mixed-lineage Exon 12 -/mice indicates normal spatial learning and mild anxiety. Mixed-lineage mice were tested for anxiety in the open-field maze and spatial learning and anxiety in the Barnes maze. Open-field measurements included (a) center-to-wall time ratio, (b) total distance traveled in centimeters, $(\mathbf{c})$ the amount of ambulatory time. The Barnes maze measurements included (d) the percentage of mice that entered the goal box, (e) the percentage of mice finding and investigating the goal, (f) the average time to find and investigate the goal for all trials, and (g) the average time to find the goal for each trial. For Barnes maze data, the number of mice to accomplish the task is represented as a percent of the total number tested. Error bars are \pm SEM. Significance of $P<0.05$ is indicated by $*$
A

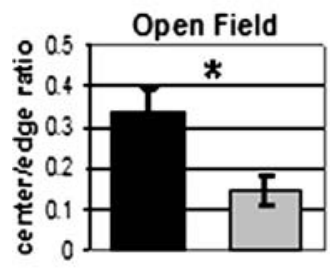

D Bames - number

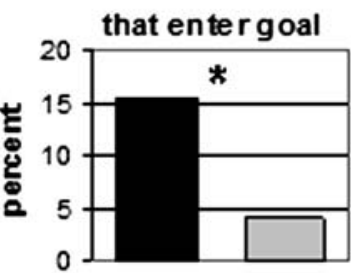

E
B Open Field -total distance

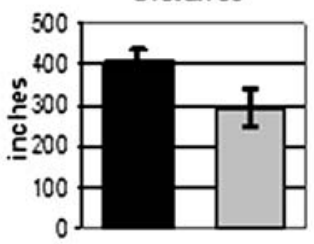

E Barnes - number that find goal
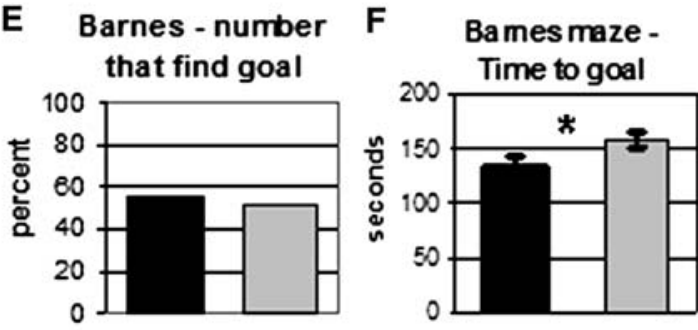
Ambulatory time

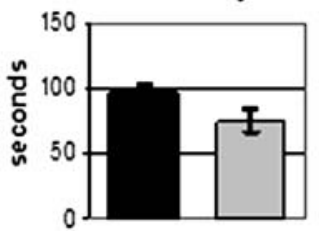$$
\text { 0 }
$$

C Open Field.

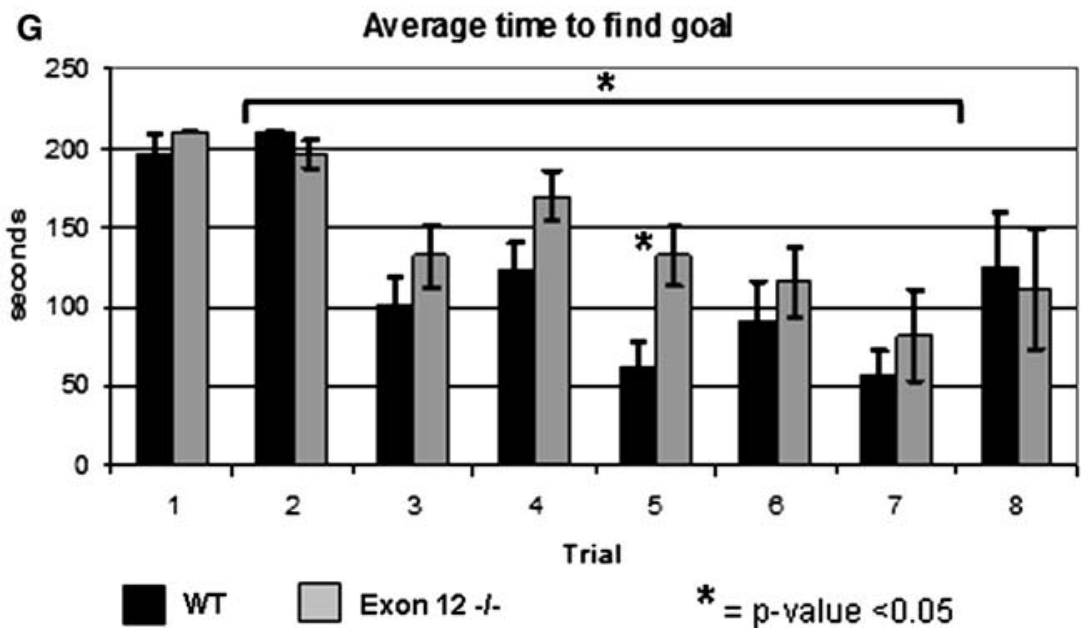

to mixed WT mice $(n=21)$. Of 122 trials, 19 mixed WT mice entered the goal box compared with only 5 mixed Exon $12-/-$ mice that entered the goal box in the same number of trials (Fig. 5d). This difference in entering the goal box was not due to difficulty locating the goal; mixed WT mice located the goal in 68 of 122 total trials, and mixed Exon $12-/-$ mice located the goal in 63 of 122 trials (Fig. 5e). Repeated trials in the Barnes maze measures spatial learning ability, as mice use visual cues within the testing room and learn to find the goal box faster on consecutive days. Mice were tested twice each day for 4 days. While the average time it took the mice to first find and investigate the goal box was statistically greater in mixed Exon $12-/-$ mice when measured as a function of the total number of trials (Fig. 5f), mixed Exon 12 -/mice and mixed WT mice decreased the amount of time to find the goal over the eight trials (see the change in average time between trials 1 and 2 compared to 7 and $8, P<0.01$ for both WT and Exon $12-/-$ mice, Fig. $5 \mathrm{~g}$ ). The mixed Exon $12-/-$ mice were significantly slower than mixed
WT mice only during trial 5; this shows that the slow phenotype is not consistent (Fig. $5 \mathrm{~g}$ ). These data suggest that the mixed Exon $12-/-$ mice were not increasingly anxious and spatial learning is not impaired. While the Exon $12-/-$ mice were able to find the goal as well as their WT counterparts, they did not enter it as often; this may be due to the impaired coordination phenotype. The high level of anxiety observed in $129 \mathrm{~Sv}$ lineage mice, both WT and Exon $12-/-$, during the open-field test was also observed in the Barnes maze test and made it an unproductive test for 129 strain mice (data not shown).

A variety of neurodegenerative diseases cause ataxia. Histological analysis of whole brain sections did not reveal any obvious differences in overall morphology between WT and Exon $12-/-$ animals in either genetic background (data not shown). Cerebellar defects are frequently associated with ataxias, so to identify potential structural changes we histologically analyzed the cerebellum. Nissl staining was performed to visualize the overall lobe structure and neuronal arrangement; this appeared to be 
normal in all analyzed Exon $12-/-$ animals (Supplementary Fig. 3a). By immunofluorescence we further studied the integrity of Purkinje cells and looked for evidence of axonal damage. We did not detect any histological abnormalities in Exon $12-/-$ cerebella and no signs of neuronal degeneration were apparent (Supplementary Fig. 3b, c).

Gene regulation by Chd6 is not completely dependent on exon 12

Chd6 has been shown to play a role in the induction of the phase-two stress response pathway (Nioi et al. 2005). Loss of exon 12 is expected to remove the ATPase function of Chd6, which should inhibit transcription of Chd6 target genes. To determine if exon 12 of Chd6 plays a critical role in the phase-two stress response, we stimulated the Nrf2 pathway in mouse embryonic fibroblasts from mixed Exon $12-/-$ and mixed WT mice. Treatment of MEF cells with compounds that stimulate stress response pathways increased expression of $\mathrm{Nqol}$ in like manner in Exon 12 $-/-$ mice and WT mice, irrespective of the stimulating compound used (Fig. 6a). The increased expression of $N r f 2$ pathway protective genes generated by the pretreatment with CDDO resulted in more efficient response upon exposure to reactive oxygen species. The level of protection, measured as the reduction in fluorescence intensity of DCFDA upon cell exposure to tBHQ, did not identify differences in the protective response of Exon $12-/-$ MEFs compared to that of WT (Fig. 6b). These results indicate that the Chd6 exon 12 is not critical for Chd6 function in the response to oxidative stress.

\section{Discussion}

Chd6 Exon 12 -/- mice are ataxic

The studies reported here demonstrate that deletion of the Chd6 exon 12 causes impaired performances in a variety of sensorimotor tests, particularly on the rotorod, ledge test, and balance beam. Several different pathological problems can contribute to sensorimotor impairment, such as lack of coordination, poor balance, bradykinesis, or poor muscle strength. Further behavioral testing indicated that only coordination and balance are impaired in Chd6 Exon $12-/-$ mice. The sensorimotor deficiency can be attributed to a lack of coordination; therefore, it can be defined as an ataxia (Gowen and Miall 2007). The ataxia phenotype can be classified, based on the affected region of the brain, as a cerebellar, sensory, vestibular, or optic ataxia. The lack of coordination is further distinguished as progressive or nonprogressive by whether the ataxia gets more severe with age.

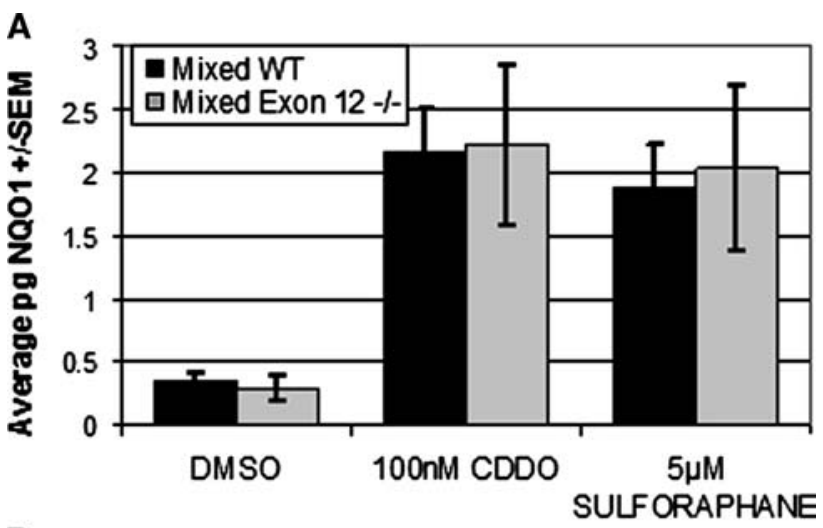

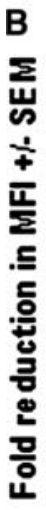

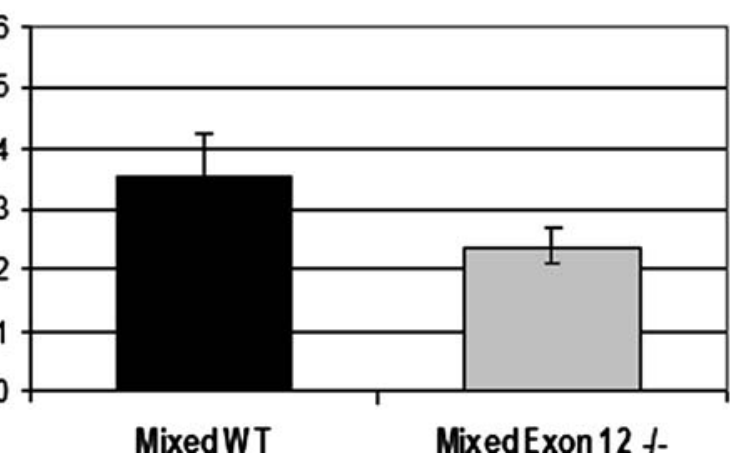

Fig. 6 Stimulation of the $N r f 2$ stress response pathway does not require the Chd6 exon 12. a Treatment of MEF cells with $N r f 2$ pathway stimulants CDDO or Sulforaphane increased the expression of Nqol in Exon 12 -/- MEF cells and WT MEFs to similar levels. qPCR analysis of the level of Nqo1 normalized to $\beta$-actin expression levels. b Increased expression of $N r f 2$ target genes results in protection from ROS challenge at similar levels in Exon $12-/-$ MEF cells and WT MEF cells. MEFs pretreated with control or CDDO were labeled with DCFDA and challenged with tBHQ. The level of DCFDA fluorescence was measured by FACScan, and the change in mean fluorescence intensity was measured as treated over untreated levels. The average of six experiments is shown

Many mutations that cause cerebellum degeneration result in an ataxic phenotype (Chakrabarti et al. 2008; Cheron et al. 2008; Dusart et al. 2006; Harkins and Fox 2002; Millen and Gleeson 2008). The ataxia of Chd6 Exon 12 -/- mice is not noticeably progressive and does not change significantly with age. Combined, our results demonstrate a deficiency in the coordination and balance of Chd6 Exon $12-/-$ mice that most likely represents cerebellar ataxia.

While the cerebellum is responsible for many functions in the brain, including sensory perception, the olfactory test demonstrated that mixed Exon $12-/-$ mice detect odor with normal efficiency, and the improved spatial learning demonstrated in the Barnes maze suggests that vision is not impaired. Morphological analysis of the brain determined that the apparent cerebellar impairment is not due to visible malformation or cell structure deficiencies, indicating that the ATPase domain of Chd6 is not a dominant factor in the regulation of genes necessary for cerebellar development 
and survival. Despite a lack of immunohistochemical evidence for cerebellar dysfunction in our current study, there is a distinct possibility that subcellular changes may affect cerebellar signaling and function as a result of exon 12 deletion altering Chd6 target gene expression levels.

CHD6 is a candidate gene for human recessive ataxias

In recent years two human ataxia mutations were mapped to regions that contain 20q12, the site of CHD6. Autosomal recessive infantile cerebellar ataxia (SCAR6 or CL3) is a nonprogressive ataxia that has been mapped to a $19.5-\mathrm{Mb}$ region on chromosome 20q11-13 (Bennetts et al. 2007; Tranebjaerg et al. 2003), a region that contains many genes, including CHD6. A balanced translocation with resulting ataxia has breakage points that map proximal to CHD6 (Hertz et al. 2004). A translocation between CHD6 and TCF4 interrupts CHD6 between exon 1 and exon 2, and the resulting phenotype has been attributed to the truncation of the TCF4 gene (Kalscheuer et al. 2008). The phenotype observed in the Chd6 Exon $12-/-$ mice makes the human CHD6 gene a promising candidate gene for the mutations that cause one or both of the ataxias, and suggests that the phenotype of the translocation patient may have multiple causes.

What little is known about Chd6 suggests its role as a chromatin-remodeling protein that interacts with several partners (Lutz et al. 2006). These partners include transcription factor $N R F 2$ of the stress response pathway, and its target gene NQO1.(Nioi et al. 2005). Loss of exon 12 is expected to remove ATPase activity from Chd6, which in turn may affect transcriptional regulation of Chd6 target genes. To determine whether loss of exon 12 affects the Chd6/Nrf2 interaction, we assayed the stress response signaling pathway in mouse embryonic fibroblasts using two different techniques for activating the stress response pathway; however, there was no significant difference in either test suggesting that exon 12 is not necessary for the role Chd6 plays in regulation of the Nrf2 stress response pathway. The difference between our results and those of Nioi et al. (2005) could have a number of explanations. The functional interaction of CHD6 and NRF2 in regulating stress response genes in human cells was acting on the pathway in a dominant negative manner. It is possible that the ATPase domain is not required for the functional involvement of Chd6 in the pathway. And finally, it is possible that the pathways do not function identically in a specific human cancer cell line (Hela), as studied by Nioi et al., and in primary mouse cells, as studied here.

Although Chd6 is expressed ubiquitously, the only consistent phenotype appears to be the impairment in sensorimotor performance. The hypothesis that initiated these studies was that chromatin remodeling by the ATPase domain was the central function of Chd6. Based on the compiled biochemical analyses of mutations within the highly conserved motif I of the ATPase domain (Richmond and Peterson 1996), the deletion of exon 12 eliminates the ability of $C h d 6$ to utilize ATP in the process of chromatin remodeling. The phenotype of the Chd6 Exon $12-/-$ mice may not include all the potential phenotypes of a full Chd6 null mutation. CHD proteins are large proteins that work as part of multisubunit complexes. There are several other domains within Chd6 that may have ATPase-independent functional activity, in particular, the DNA-binding domain; the BRK domain (also called TCH), the function of which is not clearly understood (Allen et al. 2007; Doerks et al. 2002); and the SANT domain, which binds to histone N-terminal domains (Aasland et al. 1996; Boyer et al. 2002, 2004). Chd6 may act as a "scaffold" protein in complexes containing other ATPase proteins. The Drosophila CHD6 homolog, kismet- $L$, colocalizes with $c h d l$ at sites of transcription initiation but does not colocalize with $c h d l$ after promoter clearance by Pol II (which is indicated by the phosphorylation of the Pol II C-terminal domain serine 5) when active transcription is occurring (Srinivasan et al. 2005). The potential for CHD6 to bind to other ATPases suggests that the ATPase activity of its binding partners could compensate for the lack of ATPase activity in the exon 12 deletion mutant described here, while the remaining domains of CHD6 contribute their usual activity. A third possible explanation for the subtle phenotype observed is the potential for redundancy in the chromatin-remodeling pathways. Finally, it is possible, though unlikely, that the deletion of exon 12 has in fact destroyed all the functionality of Chd6. A role in improving coordination has obvious selective advantage and could be the primary contribution of the Chd6 protein.

Acknowledgments This work was supported by NIH grant T32 AI07363. The authors acknowledge the assistance provided by Laurie Horne; the Dartmouth Transgenic and Genetic Construct Shared Resource; Val Galton and Cheryl Withrow for advice on behavioral analysis; Gwenn Garden for immunohistochemistry analysis; Brent Harris for the use of equipment; and Diane Genereux for help with statistical analysis.

Open Access This article is distributed under the terms of the Creative Commons Attribution Noncommercial License which permits any noncommercial use, distribution, and reproduction in any medium, provided the original author(s) and source are credited.

\section{References}

Aasland R, Stewart AF, Gibson T (1996) The SANT domain: a putative DNA-binding domain in the SWI-SNF and ADA complexes, the transcriptional co-repressor N-CoR and TFIIIB. Trends Biochem Sci 21:87-88

Allen MD, Religa TL, Freund SM, Bycroft M (2007) Solution structure of the BRK domains from CHD7. J Mol Biol $371: 1135-1140$ 
Aramaki M, Udaka T, Kosaki R, Makita Y, Okamoto N et al (2006) Phenotypic spectrum of CHARGE syndrome with CHD7 mutations. J Pediatr 148:410-414

Bagchi A, Papazoglu C, Wu Y, Capurso D, Brodt M et al (2007) CHD5 is a tumor suppressor at human 1p36. Cell 128:459-475

Bennetts JS, Rendtorff ND, Simpson F, Tranebjaerg L, Wicking C (2007) The coding region of TP53INP2, a gene expressed in the developing nervous system, is not altered in a family with autosomal recessive non-progressive infantile ataxia on chromosome 20q11-q13. Dev Dyn 236:843-852

Berardelli A, Rothwell JC, Thompson PD, Hallett M (2001) Pathophysiology of bradykinesia in Parkinson's disease. Brain 124:2131-2146

Bouet V, Freret T, Toutain J, Divoux D, Boulouard M et al (2007) Sensorimotor and cognitive deficits after transient middle cerebral artery occlusion in the mouse. Exp Neurol 203:555-567

Boyer LA, Langer MR, Crowley KA, Tan S, Denu JM et al (2002) Essential role for the SANT domain in the functioning of multiple chromatin remodeling enzymes. Mol Cell 10:935-942

Boyer LA, Latek RR, Peterson CL (2004) The SANT domain: a unique histone-tail-binding module? Nat Rev Mol Cell Biol 5:158-163

Brown E, Malakar S, Krebs JE (2007) How many remodelers does it take to make a brain? Diverse and cooperative roles of ATPdependent chromatin-remodeling complexes in development. Biochem Cell Biol 85:444-462

Bultman S, Gebuhr T, Yee D, La Mantia C, Nicholson J et al (2000) A Brg1 null mutation in the mouse reveals functional differences among mammalian SWI/SNF complexes. Mol Cell 6:1287-1295

Chakrabarti L, Neal JT, Miles M, Martinez RA, Smith AC et al (2006) The Purkinje cell degeneration 5J mutation is a single amino acid insertion that destabilizes Nnal protein. Mamm Genome 17:103-110

Chakrabarti L, Eng J, Martinez RA, Jackson S, Huang J et al (2008) The zinc-binding domain of Nnal is required to prevent retinal photoreceptor loss and cerebellar ataxia in Purkinje cell degeneration (pcd) mice. Vision Res 48:1999-2005

Chen YT, Collins LL, Uno H, Chang C (2005) Deficits in motor coordination with aberrant cerebellar development in mice lacking testicular orphan nuclear receptor 4. Mol Cell Biol 25:2722-2732

Cheron G, Servais L, Dan B (2008) Cerebellar network plasticity: from genes to fast oscillation. Neuroscience 153:1-19

Citterio E, Rademakers S, van der Horst GT, van Gool AJ, Hoeijmakers JH et al (1998) Biochemical and biological characterization of wild-type and ATPase-deficient Cockayne syndrome B repair protein. J Biol Chem 273:11844-11851

Citterio E, Van Den Boom V, Schnitzler G, Kanaar R, Bonte E et al (2000) ATP-dependent chromatin remodeling by the Cockayne syndrome B DNA repair-transcription-coupling factor. Mol Cell Biol 20:7643-7653

Cook MN, Bolivar VJ, McFadyen MP, Flaherty L (2002) Behavioral differences among 129 substrains: implications for knockout and transgenic mice. Behav Neurosci 116:600-611

Crawley JN (2007) What's wrong with my mouse? Behavioral phenotyping of transgenic and knockout mice, 2nd edn. WileyInterscience, Hoboken, $\mathrm{NJ}$

Crawley JN (2008) Behavioral phenotyping strategies for mutant mice. Neuron 57:809-818

de la Serna IL, Ohkawa Y, Imbalzano AN (2006) Chromatin remodelling in mammalian differentiation: lessons from ATPdependent remodellers. Nat Rev 7:461-473

Delmas V, Stokes DG, Perry RP (1993) A mammalian DNA-binding protein that contains a chromodomain and an SNF2/SWI2-like helicase domain. Proc Natl Acad Sci USA 90:2414-2418
Doerks T, Copley RR, Schultz J, Ponting CP, Bork P (2002) Systematic identification of novel protein domain families associated with nuclear functions. Genome Res 12:47-56

Durr H, Korner C, Muller M, Hickmann V, Hopfner KP (2005) X-ray structures of the Sulfolobus solfataricus SWI2/SNF2 ATPase core and its complex with DNA. Cell 121:363-373

Dusart I, Guenet JL, Sotelo C (2006) Purkinje cell death: differences between developmental cell death and neurodegenerative death in mutant mice. Cerebellum 5:163-173

Eisen JA, Sweder KS, Hanawalt PC (1995) Evolution of the SNF2 family of proteins: subfamilies with distinct sequences and functions. Nucleic Acids Res 23:2715-2723

Fujita T, Igarashi J, Okawa ER, Gotoh T, Manne J et al (2008) CHD5, a tumor suppressor gene deleted from $1 \mathrm{p} 36.31$ in neuroblastomas. J Natl Cancer Inst 100:940-949

Gowen E, Miall RC (2007) The cerebellum and motor dysfunction in neuropsychiatric disorders. Cerebellum 6:268-279

Hagenbuch N, Feldon J, Yee BK (2006) Use of the elevated plusmaze test with opaque or transparent walls in the detection of mouse strain differences and the anxiolytic effects of diazepam. Behav Pharmacol 17:31-41

Hall JA, Georgel PT (2007) CHD proteins: a diverse family with strong ties. Biochem Cell Biol 85:463-476

Harkins AB, Fox AP (2002) Cell death in weaver mouse cerebellum. Cerebellum 1:201-206

Hertz JM, Sivertsen B, Silahtaroglu A, Bugge M, Kalscheuer V et al (2004) Early onset, non-progressive, mild cerebellar ataxia cosegregating with a familial balanced translocation $\mathrm{t}(8 ; 20)$ (p22;q13). J Med Genet 41:e25

Hsieh J, Gage FH (2005) Chromatin remodeling in neural development and plasticity. Curr Opin Cell Biol 17:664-671

Iwamoto T, Okumura S, Iwatsubo K, Kawabe J, Ohtsu K et al (2003) Motor dysfunction in type 5 adenylyl cyclase-null mice. J Biol Chem 278:16936-16940

Kalscheuer VM, Feenstra I, Van Ravenswaaij-Arts CM, Smeets DF, Menzel C et al (2008) Disruption of the TCF4 gene in a girl with mental retardation but without the classical Pitt-Hopkins syndrome. Am J Med Genet A 146A:2053-2059

Khavari PA, Peterson CL, Tamkun JW, Mendel DB, Crabtree GR (1993) BRG1 contains a conserved domain of the SWI2/SNF2 family necessary for normal mitotic growth and transcription. Nature 366:170-174

Koch JD, Miles DK, Gilley JA, Yang CP, Kernie SG (2008) Brief exposure to hyperoxia depletes the glial progenitor pool and impairs functional recovery after hypoxic-ischemic brain injury. J Cereb Blood Flow Metab 28:1294-1306

Kulkarni S, Nagarajan P, Wall J, Donovan DJ, Donell RL et al (2008) Disruption of chromodomain helicase DNA binding protein 2 (CHD2) causes scoliosis. Am J Med Genet A 146A:1117-1127

Laurent BC, Treich I, Carlson M (1993) The yeast SNF2/SWI2 protein has DNA-stimulated ATPase activity required for transcriptional activation. Genes Dev 7:583-591

Lein ES, Hawrylycz MJ, Ao N, Ayres M, Bensinger A et al (2007) Genome-wide atlas of gene expression in the adult mouse brain. Nature 445:168-176

Lutz T, Stöger R, Nieto A (2006) CHD6 is a DNA-dependent ATPase and localizes at nuclear sites of mRNA synthesis. FEBS Lett 580:5851-5857

Marfella CG, Imbalzano AN (2007) The Chd family of chromatin remodelers. Mutat Res 618:30-40

Marfella CG, Ohkawa Y, Coles AH, Garlick DS, Jones SN et al (2006) Mutation of the SNF2 family member Chd2 affects mouse development and survival. J Cell Physiol 209:162-171

Matsuura K, Kabuto H, Makino H, Ogawa N (1997) Pole test is a useful method for evaluating the mouse movement disorder 
caused by striatal dopamine depletion. J Neurosci Methods 73:45-48

McFadyen MP, Kusek G, Bolivar VJ, Flaherty L (2003) Differences among eight inbred strains of mice in motor ability and motor learning on a rotorod. Genes Brain Behav 2:214-219

Millen KJ, Gleeson JG (2008) Cerebellar development and disease. Curr Opin Neurobiol 18:12-19

Nagy A (2003) Manipulating the mouse embryo: a laboratory manual, 3rd edn. Cold Spring Harbor Laboratory Press, Cold Spring Harbor, NY

Nioi P, Nguyen T, Sherratt PJ, Pickett CB (2005) The carboxyterminal Neh3 domain of Nrf2 is required for transcriptional activation. Mol Cell Biol 25:10895-10906

Ogawa N, Hirose Y, Ohara S, Ono T, Watanabe Y (1985) A simple quantitative bradykinesia test in MPTP-treated mice. Res Commun Chem Pathol Pharmacol 50:435-441

Pagon RA, Graham JM Jr, Zonana J, Yong SL (1981) Coloboma, congenital heart disease, and choanal atresia with multiple anomalies: CHARGE association. J Pediatr 99:223-227

Picketts DJ, Higgs DR, Bachoo S, Blake DJ, Quarrell OW et al (1996) ATRX encodes a novel member of the SNF2 family of proteins: mutations point to a common mechanism underlying the ATR-X syndrome. Hum Mol Genet 5:1899-1907

Richmond E, Peterson CL (1996) Functional analysis of the DNAstimulated ATPase domain of yeast SWI2/SNF2. Nucleic Acids Res 24:3685-3692

Schuster EF, Stöger R (2002) CHD5 defines a new subfamily of chromodomain-SWI2/SNF2-like helicases. Mamm Genome 13:117-119

Singleton MR, Wigley DB (2002) Modularity and specialization in superfamily 1 and 2 helicases. J Bacteriol 184:1819-1826

Srinivasan S, Armstrong JA, Deuring R, Dahlsveen IK, McNeill H et al (2005) The Drosophila trithorax group protein Kismet facilitates an early step in transcriptional elongation by RNA Polymerase II. Development 132:1623-1635

Su AI, Wiltshire T, Batalov S, Lapp H, Ching KA et al (2004) A gene atlas of the mouse and human protein-encoding transcriptomes. Proc Natl Acad Sci U S A 101:6062-6067
Thoma NH, Czyzewski BK, Alexeev AA, Mazin AV, Kowalczykowski SC et al (2005) Structure of the SWI2/SNF2 chromatinremodeling domain of eukaryotic Rad54. Nat Struct Mol Biol 12:350-356

Thompson PM, Gotoh T, Kok M, White PS, Brodeur GM (2003) CHD5, a new member of the chromodomain gene family, is preferentially expressed in the nervous system. Oncogene 22:1002-1011

Thompson BA, Tremblay V, Lin G, Bochar DA (2008) CHD8 is an ATP-dependent chromatin remodeling factor that regulates betacatenin target genes. Mol Cell Biol 28:3894-3904

Tranebjaerg L, Teslovich TM, Jones M, Barmada MM, Fagerheim T et al (2003) Genome-wide homozygosity mapping localizes a gene for autosomal recessive non-progressive infantile ataxia to 20q11-q13. Hum Genet 113:293-295

Vissers LE, van Ravenswaaij CM, Admiraal R, Hurst JA, de Vries BB et al (2004) Mutations in a new member of the chromodomain gene family cause CHARGE syndrome. Nat Genet 36:955-957

Wada T, Kubota T, Fukushima Y, Saitoh S (2000) Molecular genetic study of Japanese patients with X-linked alpha-thalassemia/ mental retardation syndrome (ATR-X). Am J Med Genet 94:242-248

Walker JE, Saraste M, Runswick MJ, Gay NJ (1982) Distantly related sequences in the alpha- and beta-subunits of ATP synthase, myosin, kinases and other ATP-requiring enzymes and a common nucleotide binding fold. EMBO J 1:945-951

White PS, Thompson PM, Gotoh T, Okawa ER, Igarashi J et al (2005) Definition and characterization of a region of $1 \mathrm{p} 36.3$ consistently deleted in neuroblastoma. Oncogene 24:2684-2694

Williams CJ, Naito T, Arco PG, Seavitt JR, Cashman SM et al (2004) The chromatin remodeler Mi-2beta is required for CD4 expression and $\mathrm{T}$ cell development. Immunity 20:719-733

Yoshida T, Hazan I, Zhang J, Ng SY, Naito T et al (2008) The role of the chromatin remodeler Mi-2beta in hematopoietic stem cell self-renewal and multilineage differentiation. Genes Dev 22:1174-1189 